\title{
Prospective analysis of the predictors of glaucoma following surgery for congenital and infantile cataract
}

\author{
Shantha Balekudaru ${ }^{1} \cdot$ Sumita Agarkar ${ }^{2} \cdot$ Sujatha Guha ${ }^{2} \cdot$ Rishikesh Charudatta Mayee $^{2} \cdot$ Natarajan Viswanathan $^{1}$. \\ Amit Pandey ${ }^{1} \cdot$ Maneesh Singh ${ }^{1} \cdot$ Vijaya Lingam ${ }^{1} \cdot$ Ronnie George $^{1}$
}

Received: 3 March 2018 / Revised: 8 October 2018 / Accepted: 2 December 2018 / Published online: 18 December 2018

(c) The Royal College of Ophthalmologists 2018

\begin{abstract}
Purpose A prospective longitudinal cohort study was performed to assess the incidence of and risk factors for the development of glaucoma following surgery for congenital/infantile cataract.

Methods One hundred and one eyes of one hundred and one children, $\leq 12$ years of age who had follow-up of $\geq 24$ months were included. Group I included those who underwent surgery using an anterior approach, group II included those who underwent surgery using a posterior approach, and group III included those who underwent surgery using an anterior approach along with foldable intraocular lens implantation. Standard definitions for glaucoma and glaucoma suspect were used. The Cox proportional hazard model was used to analyze risk factors for glaucoma.

Results Group I: 30 eyes (29.7\%); group II: 11 eyes (10.9\%); group III 60 eyes $(59.4 \%)$. The incidence of glaucoma + glaucoma suspect was 7.9\% (95\% CL: 2.6, 13.2\%) in the entire group. The incidence in group I was $16.7 \%$ (95\% CL 3\%, $30 \%$ ), in group II was $18.2 \%$ (95\% CL: 0, 41\%) and in group III was 1.7\% (95\% CL: 0, 4.9\%). Gonioscopy revealed high iris insertion with grade I (modified Shaffer grading) in one eye each in the glaucoma and glaucoma suspect group and open angles in the rest. Age at surgery of $\leq 3$ months (HR: 6.6, 95\% CL: 1.4, 30.6, $p=0.01$ ) was found to be a significant risk factor within the aphakic group.

Conclusions Younger age at the time of surgery was the only identifiable risk factor for glaucoma.
\end{abstract}

Glaucoma remains one of the serious vision-threatening complications following surgery for congenital and infantile cataract with the incidence varying from 2 to $60 \%$ [1-7]. Variations in the incidence reflect differences in the study populations, in the definitions of glaucoma used, in the techniques of cataract surgery performed, as well as the duration of follow-up reported. Risk factors reported for the development of glaucoma include younger age at the

Supplementary information The online version of this article (https:// doi.org/10.1038/s41433-018-0316-8) contains supplementary material, which is available to authorized users.

Shantha Balekudaru

shantha.acharya@gmail.com

drbs@snmail.org

1 Department of Glaucoma, Sri Jadhavbhai Nathmal Singhvi, Sankara Nethralaya, New No: 41, old no: 18 College Road, Nungambakkam, Chennai 600006 Tamil Nadu, India

2 Department of Pediatric ophthalmology, Medical Research Foundation, Sankara Nethralaya, Chennai, India time of surgery, microcornea, persistent fetal vasculature, aphakia, inflammation, type of cataract, bilateral cataract, number of additional surgeries performed and a longer follow-up period [8-13]. There is, however, a paucity of information on the baseline characteristics of patients which may influence the outcome of surgery with regard to the development of glaucoma, such as central corneal thickness (CCT), preoperative horizontal corneal diameter (HCD, axial length (AXL) and preoperative gonioscopic features.

We performed a prospective study on the incidence of and risk factors for the development of glaucoma following surgery for congenital/infantile cataract in children who underwent a detailed preoperative assessment.

\section{Methods}

A prospective non-randomized, interventional, longitudinal cohort study on children who underwent surgery for congenital/infantile cataract and who were recruited during the period January 2006 to December 2007 was performed. 
Approval for the study was obtained from the Institutional Review Board and Ethics committee. Informed consent for the surgery was provided by the parents or legal guardian.

Children $\leq 12$ years of age, at the time of surgery, with a minimum follow-up period of 2 years in the study were included. Children with traumatic, steroid induced, complicated cataracts, and cataract in children with systemic syndromes such as rubella, Lowe's syndrome, or with ocular anomalies such as persistent hyperplastic primary vitreous (PHPV), anterior segment dysgenesis, aniridia, etc, likely to be associated with the development of glaucoma, were excluded. Prematurity ( $<36$ weeks of gestation), horizontal corneal diameter of $<9 \mathrm{~mm}$, and IOP $>22 \mathrm{mmHg}$ (measured under general anesthesia before intubation) were also reasons for exclusion. In those with bilateral cataracts, the first eye to have undergone surgery was included in the analysis.

All children underwent an initial screening office assessment. Visual acuity was assessed using Lea's symbols in pre-verbal children and Snellen chart whenever possible. Visual acuity was recorded using central steady maintained fixation method (CSM) in the rest [14]. B-scan ultrasound examination (Sonomed Escalon, NY, USA) was performed prior to cataract surgery if media haze precluded fundus evaluation.

A detailed examination under anesthesia was performed prior to surgery for all patients and the data obtained were used as baseline information in the analysis. IOP measurements were taken prior to intubation using a Perkin's applanation tonometer (Haag Streit-UK ltd. Essex). Anterior segment examination was performed using a hand held slit lamp biomicroscope (Kowa company ltd, Hamamatsu city, Japan) gonioscopy using Koeppe's goniolens (Ocular Instruments Inc. Bellevue, Washington, USA) and posterior segment examination using an indirect ophthalmoscope with a 20- Diopter Volk lens (Volk Optical Inc., Ohio, and USA). The modified Shaffer grading was used to describe the gonioscopic features i.e. grades I, II, III, and IV were assigned to a peripheral angle width of $10^{\circ}, 20^{\circ}, 30^{\circ}$, and $40^{\circ}$, respectively [15]. High iris insertion was defined as insertion of the iris to the trabecular meshwork such that the sclera spur was not visible [16]. Other gonioscopic features were also noted. Measurements of central corneal thickness (CCT) and axial length (AXL) were obtained with the Ocuscan, Alcon Laboratories, Inc, Fort Worth, Texas, USA. The mean of ten measurements was used for the CCT and AXL measurements. No adjustments for IOP measuring were made based on pachymetry measurements. The horizontal corneal diameter (HCD) was measured using Castroviego callipers.

The definitions of glaucoma were based on those used in the Infant aphakia treatment study (IATS) and recommended by the World glaucoma Association consensus statement on childhood glaucoma [17-19]. Diagnosis of glaucoma was made if the IOP was $>21 \mathrm{mmHg}$, with one or more of the following features; (a) corneal enlargement, (b) myopic shift in refraction accompanied by corneal enlargement and or increase in axial length, (c) increased optic nerve cupping by a factor of $\geq 0.2$ ) or a surgical procedure having been performed for the management of glaucoma.

\section{Glaucoma suspect}

The diagnosis of glaucoma suspects was based on the following criteria: (a) the IOP was $>21 \mathrm{mmHg}$ on at least 2 separate occasions after topical steroids had been discontinued, (b) if IOP lowering agents had been used to manage elevated IOP, (c) suspicious optic disc appearance for glaucoma, and (d) increased horizontal corneal diameter or axial length in the setting of normal IOP.

The practice pattern for the management of congenital and infantile cataract, which was prevalent in our institution at the time of the initiation of this study was followed in our cohort. Children less than 24 months of age at the time of surgery were left aphakic and those who were older than 24 months of age underwent IOL implantation. Group I included children who underwent surgery using an anterior approach, group II included those who underwent surgery using a posterior approach, and group III included those who underwent surgery using an anterior approach followed by intraocular lens implantation. The details of the surgical technique are described below.

\section{Group I}

Two stab incisions were made at 2 o'clock and 10 o'clock positions anterior capsulorhexis was performed under cover of an oculo viscosurgical device (OVD) using sodium hyaluronidate 7000 or sodium hyaluronate 5000 (Abbott Medical Optics ltd), followed by lens aspiration using a bimanual irrigation-aspiration system. Central posterior capsulorhexis (PCCC) was then performed under cover of an OVD, followed by anterior vitrectomy through this opening. The two incisions were closed using either 10 ' $\mathrm{O}$ ' monofilament nylon or 10 '0'polyglactin sutures. This approach was used by the pediatric ophthalmologists.

\section{Group II}

Pars plicata approach: Lensectomy with anterior vitrectomy was performed using three sclerotomies placed at $1-1.5 \mathrm{~mm}$ from the limbus. After placing an infusion cannula in the inferotemporal quadrant, lensectomy, and limited anterior vitrectomy was performed. A peripheral rim of the anterior 
capsule was retained to facilitate IOL implantation. This approach was used by the vitreo-retinal surgeons.

\section{Group III}

A similar procedure was performed in children over 2 years of age, in addition to which a superior $2.8 \mathrm{mms}$ sclera tunnel was fashioned to facilitate intraocular lens implantation. Following anterior vitrectomy, OVD was injected into the capsular bag. Foldable intraocular lenses (IOLs) were inserted into the bag (either acrylic single piece hydrophobic lenses, Acrysof, model: SA6OAT; Alcon laboratories 1td, or 3 piece acrylic hydrophobic lenses (Sensar, model AR40e, Abbot Medical Optics Inc.) under OVD cover.

Details of intra operative complications were noted. The postoperative regimen consisted of cycoplegic agents such as homatropine hydrobromide $2 \%$ or atropine sulphate $1 \%$ and topical steroids such as $1 \%$ prednisolone acetate, starting at a dose of 10 times per day, tapered over a period of 6-8 weeks. Children were assessed on the first post operative day, a second review within the first post operative week, at 6 weeks and at regular intervals of 4-6 months thereafter. Visual acuity, cyclopegic refraction, IOP measurement, slit lamp biomicroscopy, optic disc, and fundus evaluation, was performed at each visit. IOP measurements were obtained using Perkin's applanation tonometry under sedation with pedichloryl syrup (dosage $50 \mathrm{mg} / \mathrm{kg}$ body weight) in those who were too young to cooperate for examination. Goldmann applanation tonmetry was used in the remainder. Central corneal thickness and axial length measurements were obtained once a year. Early postoperative ( $\leq 6$ weeks) and late postoperative complications ( $>6$ weeks) and details of their management were noted. All children were evaluated in the glaucoma clinic for evidence of glaucoma throughout the study.

\section{Statistical methods}

The Statistical Package for the social sciences (SPSS) version 14: SPSS Inc. Chicago, released 2007, was used for the analysis. The sample size, calculated for an expected incidence of glaucoma of $15 \%$, with $80 \%$ power and $\alpha$ error of 0.05 was 87 . The data obtained were analyzed after a follow-up period of 6 years.

Continuous variables were compared using a paired independent $t$-test and categorical variables using either a $\chi^{2}$ - or Fisher's exact test. Non-parametric tests such as the Mann-Whitney $U$-test and Wilcoxon rank test were used for variables which were not normally distributed. The significance level was set at $p<0.05$. The Cox proportional hazard model was used to assess risk factors for the development of glaucoma. Manifest glaucoma cases and glaucoma suspects (ocular hypertensive eyes on treatment with IOP lowering medications) were grouped together for the risk analysis. Groups I and II were grouped together for the analysis of risk factors for glaucoma within the group.

\section{Results}

\section{Baseline demographic data}

The baseline demographics of the three groups are depicted in Table 1 . The majority of eyes $(90,89.1 \%)$ had open angles. Eleven of these had prominent iris processes and one had a concave wrap around iris configuration; 2 had moderately pigmented trabecular meshwork. Trabeculodysgenesis in the form of high iris insertion was seen in $8(19.5 \%)$ eyes in groups I and II and in 4 eyes $(6.7 \%)$ in group III $(p=0.05)$. There were no significant differences in the baseline demographics between groups I and II except for gonioscopy grade, horizontal corneal diameter, and the duration of follow-up.

There was a positive correlation with age and horizontal corneal diameter $(r=0.41, p<0.005)$ and axial length $(r=$ $0.59, p<0.05)$. Younger age $(13.3 \pm 18.1$ months $)$ was associated with an angle grade of $\leq 2$ compared to open angles of $>$ grade II $(41.4 \pm 32.7$ months $) p=0.004$. High iris insertion was also associated with younger age (12.8 \pm 17.5 months) compared to normal iris insertion with open angles $(41.7 \pm 32.7$ months $) p=0.002$.

Associated ocular anomalies are depicted in Table 2. Most complications were transient and were managed conservatively (Table 3). All children in group III had IOL inserted within the capsular bag. Secondary surgical procedures apart from glaucoma surgery included secondary intraocular lens implantation in 10 children, strabismus surgery in 2 children and surgical treatment of retinal detachment in 3 children. Four eyes, 2 in group II and two in group III developed posterior capsular opacification which required YAG laser capsulotomy. None of these eyes developed glaucoma.

\section{Development of glaucoma}

The cumulative incidence of glaucoma + glaucoma suspect was $7.9 \%$ (95\% CL: $2.6 \%, 9.2 \%)$. The incidence in group I was $16.7 \%$ (95\% CL: $3 \%, 30 \%$ ), in group II was $18.2 \%$ (95\% CL: 0, 41\%), and in group III was $1.7 \%$ (95\% CL 0, $4.9 \%)$. The cumulative incidence of glaucoma was $3 \%$ (95\% CL: $0,6.3 \%$ ) and of glaucoma suspects was $5 \%$ (95\% CL: 0.7, 9.2\%). Two eyes in group I and one eye in group II developed glaucoma as defined. Glaucoma suspects were seen in 3 eyes in group I, one in group II, and one in group III. 
Table 1 Baseline demographics of the three groups

\begin{tabular}{|c|c|c|c|c|}
\hline & $\begin{array}{l}\text { Group I } \\
N=30 \text { eyes }\end{array}$ & $\begin{array}{l}\text { Group II } \\
N=11 \text { eyes }\end{array}$ & $\begin{array}{l}\text { Significance (Comparison } \\
\text { between groups I and II) }\end{array}$ & $\begin{array}{l}\text { Group III } \\
N=60 \text { eyes }\end{array}$ \\
\hline \multicolumn{5}{|l|}{ Age (months) } \\
\hline Mean & $9.2 \pm 8.5$ & $6.6 \pm 3.2$ & 0.51 & $57 \pm 27.5$ \\
\hline Range & $2-48$ & $1-10$ & & $24-120$ \\
\hline Male:Female & $18: 12$ & $8: 3$ & 0.45 & $40: 20$ \\
\hline \multicolumn{5}{|l|}{ Gonioscopy grade } \\
\hline$<$ Grade II & 3 & 4 & 0.04 & 4 \\
\hline$>$ Grade II & 27 & 7 & & 56 \\
\hline $\begin{array}{l}\text { Gonioscopic features } \\
\text { High iris Insertion }\end{array}$ & 5 & 3 & 0.44 & 4 \\
\hline $\begin{array}{l}\text { Applanation tonometry } \\
\text { in } \mathrm{mmHg} \text { : Mean (SD) }\end{array}$ & $10.4 \pm 3.7$ & $11.2 \pm 4.6$ & 0.75 & $11.5 \pm 3.9$ \\
\hline $\begin{array}{l}\text { Central corneal } \\
\text { thickness (microns) } \\
\text { Mean (SD) }\end{array}$ & $532.8 \pm 31.1$ & $555.9 \pm 36.7$ & 0.11 & $534.4 \pm 47.7$ \\
\hline $\begin{array}{l}\text { Axial length (mms) } \\
\text { Mean (SD) }\end{array}$ & $19.6 \pm 2$ & $18.5 \pm 1.4$ & 0.06 & $22.5 \pm 2.1$ \\
\hline Unilateral cataract & 4 & 2 & 0.69 & 10 \\
\hline Bilateral cataract & 26 & 9 & & 50 \\
\hline \multicolumn{5}{|l|}{ Type of cataract } \\
\hline Total & 16 & 8 & 0.35 & 8 \\
\hline Nuclear & 1 & 1 & & 5 \\
\hline Zonular & 9 & 2 & & 34 \\
\hline Posterior & 2 & & & 5 \\
\hline Subcapsular & 0 & & & 4 \\
\hline Posterior polar cortical & 2 & & & 4 \\
\hline $\begin{array}{l}\text { Horizontal corneal } \\
\text { diameter }(\mathrm{mms}) \\
\text { Mean }(\mathrm{SD})\end{array}$ & $10.8 \pm 0.9$ & $10.1 \pm 0.9$ & 0.04 & $11.3 \pm 0.7$ \\
\hline $\begin{array}{l}\text { Follow-up period (years) } \\
\text { Mean (SD) }\end{array}$ & $6.4 \pm 2.1$ & $7.64 \pm 2.1$ & 0.004 & $6.5 \pm 3.5$ \\
\hline
\end{tabular}

Table 2 Ocular and systemic associations

\begin{tabular}{lll}
\hline & Groups I and II & Group III \\
\hline Systemic disorders & & \\
Microcephaly & 1 & 0 \\
Atrial septal defect & 0 & 1 \\
Epilepsy & 0 & 2 \\
Status post meningitis & 0 & 1 \\
Ocular anomalies & & \\
Strabismus & 5 & 5 \\
Nystagmus & 18 & 10 \\
Nasolacrimal duct obstruction & 0 & 1 \\
Posterior lenticonus & 1 & 2 \\
\hline
\end{tabular}

Time to diagnosis was mean of $19 \pm 20.6$ months for glaucoma and mean of $26.8 \pm 25.8$ months for glaucoma suspects. The mean IOP at the time of diagnosis in $\mathrm{mmHg}$ was $29.6 \pm 5.4$, with a median of $30 \mathrm{mmHg}$ and IQR of
Table 3 Complications

\begin{tabular}{llll}
\hline & Group I & Group II & Group III \\
\hline Intraoperative & & & \\
Extension of anterior capsulorhexis & $1(3.3 \%)$ & 0 & $5(8.3 \%)$ \\
Vitreous hemorrhage & 0 & 0 & $1(1.6 \%)$ \\
Buttonhole formation in scleral flap & 0 & 0 & $1(1.6 \%)$ \\
Post operative & & & \\
Inflammation & $1(3.3) \%$ & 0 & \\
Retinal detachment & $1(3.3 \%)$ & 0 & $3(5 \%)$ \\
Retinal hemorrhages & $1(3.3 \%)$ & 0 & $1(1.6 \%)$ \\
Hyphema & $1(3.3 \%)$ & 0 & $1(1.6 \%)$ \\
Corneal edema + inflammation & 0 & 1 & $1(1.6 \%)$ \\
\hline
\end{tabular}

$10.8 \mathrm{mmHg}$. The gonioscopy details of these patients at baseline were as follows: one eye with glaucoma had Shaffer grading II with high iris insertion and the other two had Shaffer grading III with prominent iris processes. Four 
Fig. 1 Kaplan-Meier curves showing cumulative probability of glaucoma and glaucoma suspect plotted against time (years)

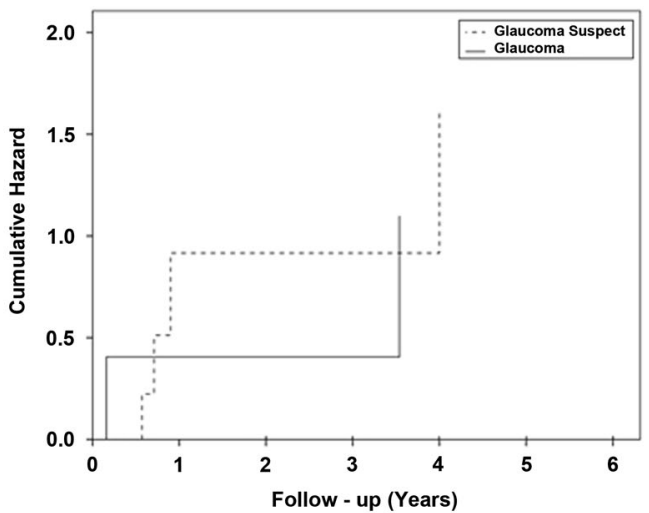

\begin{tabular}{|l|l|l|l|l|l|l|}
\hline $\begin{array}{l}\text { Duration of } \\
\text { follow-up } \\
\text { (years) }\end{array}$ & $\mathbf{1}$ & $\mathbf{2}$ & $\mathbf{3}$ & $\mathbf{4}$ & $\mathbf{5}$ & 6 \\
\hline $\begin{array}{l}\text { Number of } \\
\text { children }\end{array}$ & 101 & 101 & 93 & 87 & 76 & 66 \\
\hline
\end{tabular}

of the glaucoma suspects had Shaffer grading III with prominent iris processes and one had Shaffer grading II with high iris insertion. The earliest onset of glaucoma was at 2 months following surgery in a child whose age at the time of surgery was 4 months.

Treatment for elevated IOP was required in eight eyes. This involved medical therapy in 2 eyes with glaucoma and 5 eyes of glaucoma suspects. One child with glaucoma required External trabeculotomy + trabeculectomy with adjunctive Mitomycin C 5 months following cataract surgery, which was followed by Ahmed glaucoma valve implantation when IOP remained uncontrolled, 31 months later. The cumulative probability of developing glaucomarelated adverse events is depicted in Fig. 1.

The difference between the pre-operative characteristics and the final outcome in terms of IOP and biometry in the 3 surgical groups are depicted in supplemental Table I. The outcome at the final visit between glaucomatous and nonglaucomatous eyes is depicted in supplemental table II. Intraocular pressure (treated) and cup: disc ratio was significantly higher in the group with glaucoma.

\section{Risk factors for the development of glaucoma}

The risk factor analysis for the development of glaucoma is depicted in Table 4. On univariate analysis, only age $<3$ months at the time of surgery (Hazard ration 6.6, 95\% CL: $1.4,30.6, p=0.01)$ was a significant risk factor in the aphakic group. As only one eye in group III developed glaucoma, risk factor analysis within this group was not possible.

The differences in the preoperative characteristics and final outcomes of those who were lost to follow-up after
Table 4 Risk factors for the development of glaucoma

\begin{tabular}{llll}
\hline Variable & Hazard ratio & $95 \%$ CI & $P$-value \\
\hline Age $\leq 3$ months & 6.6 & $1.4,30.6$ & 0.02 \\
Gender: female male as reference & 0.7 & $0.1,3.8$ & 0.72 \\
$\begin{array}{l}\text { Pre-operative intra ocular } \\
\text { pressure (mmHg) }\end{array}$ & 1 & $0.8,1.2$ & 0.87 \\
$\begin{array}{l}\text { Pre-operative horizontal corneal } \\
\text { diameter (mm) } \leq 10\end{array}$ & 1.4 & $0.3,6.2$ & 0.67 \\
$\begin{array}{l}\text { Pre-operative axial length (mm) } \\
\leq 18\end{array}$ & 1.9 & $0.9,1.02$ & 0.74 \\
Pre-operative CCT & 1 & & \\
Gonioscopy grade $\leq 2$ & 0.45 & $0.4,10.6$ & 0.45 \\
High iris insertion & 1.64 & $0.3,8.9$ & 0.42 \\
Bilateral cataract & 1.26 & $0.2,10.5$ & 0.83 \\
Anterior approach (group I) & 3.4 & $0.4,30.2$ & 0.3 \\
\hline
\end{tabular}

6 years and those who were not was also analyzed (Supplemental table III). There were no significant differences between the two groups except for the surgical approach.

\section{Discussion}

Our incidence of glaucoma and glaucoma suspect was much lower than the incidence quoted in most reports in the literature [1-7]. There are several explanations for the lower incidence. The majority of the children in our series $(75,65.7 \%)$ were 12 months of age or older at the time of surgery. Younger age at the time of surgery has been reported as a risk factor for the development of glaucoma in most reports published in the literature $[10-13,17,18,20,21]$. Definitions for the diagnosis of glaucoma following 
pediatric cataract surgery vary widely $[3,10,22]$. Strict criteria used for defining glaucoma could also be responsible for the lower rates that we have reported. We also excluded all patients with systemic syndromes or ocular anomalies, which would render them more susceptible for the development of glaucoma, including Rubella, Lowe's syndrome, prematurity; eyes with PHPV, aniridia etc. [10, 23-26]. Modern surgical techniques were used, thereby reducing the risk of post operative inflammation responsible for secondary angle closure glaucoma in this age group. The use of a capsulorhexis for performing the anterior and posterior caspulotomy, in eyes in which the anterior approach was used, combined with anterior vitrectomy reduces the effect of lens epithelial cells as promoters of inflammation and posterior capsular opacification [27]. Posterior laser capsulotomy/membranectomy which have been cited as risk factors for post operative glaucoma in infantile eyes was not required in any our patients [28]. The onset of glaucoma following pediatric cataract surgery is often delayed for many years and has been reported as late as 65 years following surgery [29]. On analyzing the differences in the preoperative characteristics and final outcomes between those who were lost to follow-up after 6 years and those who were not, the difference was not statistically significant. Therefore, the loss of follow-up may not have contributed significantly to the low incidence noted in our cohort.

The only risk factor which was associated with the development of glaucoma was younger age at the time of surgery, in our series. Increasing age at the time of surgery was identified as a protective factor against the development of glaucoma (HR: $0.31,95 \%$ CL: $0.15,0.63, p<0.001$ ) in the British congenital cataract study [20]. A meta-analysis on post operative glaucoma following congenital cataract surgery reported younger age $<4$ weeks at the time of surgery, (HR: 2.10, 95\% CL: 1.14, 3.84, $p=0.02$ ) as a significant risk factor [21]. Younger age at surgery (HR: 3.2 (95\% CL: 1.2, 8.3) was reported as a risk factor in the IATS $[17,18]$. The reasons for this phenomenon are poorly understood. Poor dilation resulting in incomplete removal of lens material, obstruction of trabecular meshwork by inflammatory cells and lenticular debris, immaturity of the infantile trabeucular meshwork as well as mechanical collapse of the trabecular meshwork caused by lack of ciliary body tension in aphakic eyes have all been described as possible reasons $[22,30]$. The effect of cytokines secreted by the lens epithelial cells on the infantile trabecular meshwork has also been suggested as a possible risk factor for the development of glaucoma [31].

Ours is one of the first prospective studies to report details of pre-operative gonosicopy in children undergoing cataract surgery. Of the 12 eyes identified with high iris insertion in our series, one eye developed glaucoma, and one eye was diagnosed as a glaucoma suspect. Nishijima et al. described the ultrasound biomicropscopic features of the anterior segment of 28 eyes of patients after congenital cataract surgery [32]. The angle opening distance in cases $(174-920 \mu \mathrm{m})$ was significantly lower in glaucoma cases when compared to controls $(260-1119 \mu \mathrm{m}, p=0.0004)$. We detected 11 eyes (10.9\%) with narrow anterior chamber angles by Shaffer grading, in our series, of which 2 eyes developed elevated IOP. They also described high iris insertion in 21 eyes of which $10(47.6 \%)$ developed elevated IOP. The majority of eyes presenting with glaucoma ( $96 \%$ of 65 eyes) were characterized by forward positioning of the iris to the posterior or middle trabecular meshwork in a report by Walton et al. on pediatric apakic glaucoma [16]. Earlier reports on glaucoma following congenital cataract surgery have described one of the common mechanisms to be pupillary block more often encountered in eyes which underwent surgery using techniques, such as needling [33]. However, recent reports, using modern vitrectomy techniques describe open angle type of glaucoma in the majority $[6,17,21,34]$.

Primary IOL implantation was reported as a protective factor against the development of glaucoma in earlier reports. Only one case was diagnosed with glaucoma amongst 377 eyes in a series on primary IOL implantation in the pediatric population reported by Asrani et al. [35]. In a meta-analysis on post operative glaucoma following congenital cataract surgery, the authors report a reduced risk for pseudophakic eyes for the development of glaucoma (HR: 0.1, 95\% CL: 0.01, 0.76, $p=0.03$ ) [21]. However, all reports included in the analysis were retrospective and non-randomized. The IATS was the only randomized controlled study which randomized patients (age: 1-6 months) into an aphakic group with contact lens correction for aphakia and a pseudophakic group. At the end of 5 years, Kaplan-Meier curves for developing glaucoma or glaucoma + glaucoma suspect was not significantly different for the two groups (HR: 1.3, 95\% CL: $0.6,5.25 ; p=0.58$ ) [18]. On univariate analysis, age $<3$ months at the time of surgery, was identified as a risk factor in our cohort. All other factors analyzed were insignificant.

We found a significant increase in the IOP as well as the $\mathrm{CCT}$ at the final visit in all 3 surgical groups. The increase in CCT was higher in eyes with glaucoma when compared to controls; however, the difference was not statistically significant as the eyes with glaucoma were under treatment for elevated IOP. The IATS reported reduced endothelial densities in glaucoma cases and glaucoma suspects compared to controls $(p=0.025)$ as well as higher CCT in glaucoma cases and suspects compared to controls $(p=0.0054)$. They also reported thicker CCT in aphakic eyes $(637 \pm 54 \mu \mathrm{m})$ vs pseudophakic eyes $(605 \pm 44 \mu \mathrm{m})$ [36]. The number of eyes with glaucoma in our series is too 
small to speculate on the effects of increased CCT following surgery, on IOP measurement. The World Glaucoma Association consensus on pediatric glaucoma states that while pachymetry is an important part of the assessment of pediatric glaucoma, no adjustment should be made for CCT in the measurement of IOP [37].

The other baseline characteristics assessed as risk factors for the development of glaucoma were found to be insignificant (Table 4). The IATS identified corneal diameter $\leq 10$ vs. $>10 \mathrm{~mm}$ as a significant risk factor on multivariate analysis (HR: 2.9, 95\% CL: 1.5-5.7; $p=0.002$ ) [18]. There was a moderately high-positive correlation between age and corneal diameter in their series $(r=0.65, p<0.001)$. Other retrospective studies have found eyes with smaller corneal diameters to be at increased risk for the development of glaucoma as well [8, 9]. There was a moderate correlation with age, horizontal corneal diameter, axial length, grade, and type of gonioscopic appearance in our series as well, as described earlier.

Additional intraocular procedures performed following cataract surgery has been identified as risk factors for the development of glaucoma [38]. Pseudophakic eyes have been reported to require additional surgical procedures for the management of complications more frequently than aphakic eyes in the pediatric population. The IATS reported additional intraocular surgeries in $72 \%$ of pseudophakic patients in comparison to $16 \%$ of aphakic patients. Of the 8 eyes diagnosed with glaucoma in our series, none had undergone secondary surgical procedures prior to the diagnosis. This could be attributed to the older age at the time of surgery in pseudophakic eyes in our series.

The merits of our study were the prospective design and sufficient sample size to identify risk factors for the development of glaucoma. Our glaucoma specialists assessed all children for evidence of glaucoma during the follow-up period. Ours is one of the prospective studies to report on baseline characteristics such as central corneal thickness as well as details of angle assessment.

The demerits include the fact that the surgical intervention was not randomized. Follow-up of 6 years was present in only 66 children $(65.3 \%)$. Visual outcomes could not be assessed in many children who were pre-verbal at baseline. Measurements of CCT and axial length during follow-up were compromised by missing data.

\section{Conclusion}

We detected an incidence of glaucoma and glaucoma suspect of $7.9 \%$ in our series. We found that only younger age at the time of surgery was a significant risk factor. Therefore, pseudophakic eyes, which had all undergone surgery after 24 months of age, had lower incident rates for glaucoma compared to aphakic eyes.

\section{Summary}

What was known before:

- Glaucoma is a frequent complication of cataract surgery performed in children.

- Younger age at surgery and reduced corneal diameter are some of most frequently reported risk factors.

What this study adds:

- A large sample size.

- A detailed pre-operative evaluation which includes pachymetry and gonioscopic details for the first time.

- Prospective evaluation of the predictors of glaucoma in the population at risk.

\section{Compliance with ethical standards}

Conflict of interest The authors declare that they have no conflict of interest.

Publisher's note: Springer Nature remains neutral with regard to jurisdictional claims in published maps and institutional affiliations.

\section{References}

1. Simon JW, Mehta N, Simmons SJ, Catalano RA, Linninger CC. Glaucoma after pediatric lensectomy/vitrectomy. Ophthalmology. 1991;98:670-74.

2. Egbert JE, Wright MM, Dahlhauser KF, Keithahn MAZ, Letson RD. Summers CGl. A prospective study of ocular hypertension and glaucoma after pediatric cataract surgery. Ophthalmology. 1995;102:1098-101.

3. Tatham A, Odedra N, Anwar S, Woodruff G. The incidence of glaucoma following pediatric cataract surgery: a 20-year retrospective study. Eye. 2010;24:1366-75.

4. Wong IB, Sukthankar VD, Cortina-Borja, Nischal KK. Incidence of early-onset glaucoma after infant cataract extraction with or without intraocular lens implantation. Br J Ophthalmol. 2009;93: 1200-03.

5. Ruddle RJ, Staffieri SE, Crowston AG, Sherwin JC, Mackey DA. Incidence and predictors of glaucoma following surgery for congenital cataract in the first year of life in Victoria, Australia. Clin Exp Ophthalmol. 2013;41:653-61.

6. Lambert SR, Purohit A, Superak HM, Lynn MJ, Beck AD. Long-term risk of glaucoma after congenital cataract surgery. Am J Ophthalmol. 2013;156:355-61.

7. Baden C, Shija F, Lewallen S, Courtright P, Hall A. Glaucoma after pediatric cataract surgery in a population with limited access to care. J AAPOS. 2013;17:158-62.

8. Wallace DK, Plager DA. Corneal diameter in childhood aphakic glaucoma. J Pediatr Ophthalmol Strabismus. 1996;33:230-34. 
9. Nishina S, Noda E, Azuma N. Outcome of early surgery for bilateral congenital cataracts in eyes with microcornea. Am J Ophthalmol. 2007;144:276-80.

10. Swamy BN, Billson F, Martin F, Hing S, Smith JEH et al. Secondary glaucoma after pediatric cataract surgery. Br J Ophthalmol. 2007;91:1627-30.

11. Vishwanath M, Cheong- Leen R, Taylor D, Russel -Eggit R, Rahi J. Is early surgery for congenital cataract a risk factor for glaucoma? Br J Ophthalmol. 2004;88:905-10.

12. Kuhli-Hattenbach C, Luchtenberg M, Kohnen T, Hattenbach L. Risk factors for complications after congenital cataract surgery without intraocular lens implantation in the first 18 months of life. Am J Ophthalmol. 2008;146:1-7.

13. Khan AO, Al-Dahmesh S. Age at the time of cataract surgery and relative risk for aphakic glaucoma in nontraumatic infantile cataract. J AAPOS. 2009;13:166-69.

14. Kothari M, Bhaskare A, Mete D, Toshniwal S, Doshi P, Kaul S. Evaluation of central steady maintained fixation grading for predicting inter-eye visual acuity difference to diagnose and treat amblyopia in strabismic patients. Indian J Ophthalmol. 2009;57: 281-84.

15. Baskaran M, Oen FTS, Chang Y-H, Hoh S-J, Ho C-L, Kashiwagi $\mathrm{K}$, et al. Comparison of the scanning peripheral anterior chamber depth analyzer and the modified van Herick grading system in the assessment of angle closure. Ophthalmology. 2007;114:501-06.

16. Walton DS. Pediatric aphakic glaucoma: a study of 65 patients. Trans Am Ophthalmol Soc. 1995;93:403-13.

17. Beck AD, Freedman SF, Lynn MJ, Bothun E, Neely DE, Lambert SR. Glaucoma-related adverse events in the infantile apakia treatment study. 1-Year results. Arch Ophthalmol. 2012;130: 300-05.

18. Freedman SF, Lynn MJ, Beck AD, Bothun ED, Orge FH, Lambert SR. Glaucoma-related adverse events in the first 5 years after unilateral cataract removal in the infantile aphakia treatment study. JAMA. 2015;133:907-14.

19. Beck A, Chang T, Freedman S. Definition, classification, differential diagnosis. In: Weinreb R, Grajewski A, Papadapoulous M, Grigg J, Freedman S, editors. Childhood glaucoma: The 9th Consensus Report of the World Glaucoma Association. Amsterdam: Kugler Publications; 2013. p. 3-14. .

20. Chak M, Rahi JS. Incidence of and risk factors associated with glaucoma after surgery for congenital cataract: findings from the British congenital cataract study. Ophthalmology. 2008;115: 1013-18.

21. Mataftsi A, Haidich AB, Kokkali S, Rabiah PK, Birch E, Stager $\mathrm{DR}$, et al. Post operative glaucoma following infantile cataract surgery: an individual patient data meta-analysis. JAMA Ophthalmol. 2014;132:1059-67.

22. Papadapoulos M, Khaw PT. Meeting the challenge of glaucoma after pediatric cataract surgery. Eye. 2003;17:1-2.

23. Shah SK, Praveen MR, Vasavada AR, Vasavada VA, Carelli R, Trivedi RH. Long-term longitudinal assessment of post operative outcomes after congenital cataract surgery in children with congenital rubella syndrome. J Cataract Refract Surg. 2014;40: 2091-8.

24. Kruger SJ, Wilson ME Jr, Hutchinson AK, Peterseim MM, Bartholomeo LR, Saunders RA. Cataract and glaucoma in patients with oculo-cerebral renal syndrome. Arch Ophthalmol. 2003;121: 1234-7.

25. Bremer DC, Roberts DC, Good WV, Tung B, Hardy RJ, Fellows R. Glaucoma in the early treatment for retinopathy of prematurity (ETROP) study. J AAPOS. 2012;16:449-52.

26. Balekudaru S, Sankaranarayanan N, Agarkar S. Prevalence, incidence and risk factors for the development of glaucoma in patients with aniridia. J Paediatr Ophthalmol Strabismus. 2017;54: $250-55$.

27. Vasavada VA, Pravenn MR, Tassignon M-J, Shah SK, Vasavada VA, Vasavada VA, et al. Posterior capsule management in congenital cataract surgery. J Cataract Refract Surg. 2011;37:173-93.

28. Michaelides M, Bunce C, Adams GG. Glaucoma following congenital cataract surgery-the role of early surgery and posterior capsulotomy. BMC Ophthalmol. 2007;11:7-13.

29. Barnhorst D, Meyers SM, Myers T. Lens induced glaucoma 65 years after congenital cataract surgery. Am J Ophthalmol. 1994;118:807-8.

30. McNemainin PG. Amorphological study of the inner surface of the anterior chamber angle in pre and post natal human eyes. Curr Eye Res. 1989;8:727-39.

31. Michael I, Walton DS, Levenberg S. Infantile aphakic glaucoma; a proposed etiological role of IL-4 and VEGF. J Pediatr Ophthalmol Strabismus. 2011;48:98-107.

32. Nishijima K, Takahashi K, Yamakawa R. Ultrasound biomicroscopy of the anterior segment after congenital cataract surgery. Am J Ophthalmol. 2000;130:483-89.

33. Francois J. Late results of congenital cataract surgery. Ophthalmology. 1979;86:1586-98.

34. Chen TC, Walton DS, Bhatia LS. Aphakic glaucoma after congenital cataract surgery. Arch Ophthalmol. 2004;122:1819-25.

35. Asrani SG, Freedmann S, Hassalblad V, Buckley EG, Egbert J, Dahan E, et al. Does primary intraocular lens implantation prevent 'aphakic' glaucoma in children? J AAPOS. 2000;4:33-9.

36. Morrison DG, Lynn MJ, Freedman SF, Orge FH, Lambert SR. Corneal changes in children after unilateral cataract surgery in the infant aphakia treatment study. Ophthalmology. 2015;122: 2186-92.

37. Fenerty C, Freeman N and Grigg J. Glaucoma following cataract surgery. In: Weinreb RN,Grajenski AL, Papadapoulos M, Grigg J, Freedman S, editors. Childhood glaucoma: the $9^{\text {th }}$ consensus report of the world glaucoma association. p. 233-47, (Kugler publications; Amsterdam, The Netherlands, 2013).

38. Plager DA, Lynn MJ, Buckley EG, Wilson ME, Lambert SR. Complications in the first 5 years following cataract surgery in infants with and without intraocular lens implantation in the infant aphakia treatment study. Am J Ophthalmol. 2014;158:892-98. 